REVIEW

\title{
Teaching Young Adult Literature Today: Insights, Considerations, and Perspectives for the Classroom Teacher (second edition), Young Adult Nonfiction: Gateway to the Common Core, and Teaching Young Adult Literature: Integrating, Implementing, and Re- Imagining the Common Core
}

\author{
TERRI SUICO \\ SAINT MARY'S COLLEGE
}

The upsurge in the popularity of young adult literature (YAL) has had an exciting domino effect not just for readers but also for teachers and scholars. As the number of young adult (YA) books published has grown over the past two decades, so has YAL's presence in the classroom and in academic research, and resources for helping teachers use the texts as well as books and journals dedicated to the study of adolescent literature have become plentiful. For teachers seeking new ideas for using YAL or for academics wanting texts that connect methods to research, the choices can be overwhelming. Fortunately, Judith A. Hayn and Jeffrey S. Kaplan, along with other editors and contributors, have compiled a trio of books that ground instructional ideas for YAL with research. Taken together, the second edition of Teaching Young Adult Literature Today: Insights, Considerations, and Perspectives for the Classroom Teacher, Young Adult Nonfiction: Gateway to the Common Core, and Teaching Young Adult Literature: Integrating, Implementing, and Re-Imagining the Common Core provide a rich and relevant resource not just for classroom and pre-service teachers but also for academics looking for different approaches to integrate YAL into the secondary classroom. Furthermore, the books' attention to research provides a sound foundation to use as support for YAL's benefits or to reference in future scholarship. 


\section{Teaching Young Adult literature Today: Insights, Considerations, and Perspectives for the CLASSROOM TEACHER (SECOND EDITION)}

Teaching Young Adult Literature Today, first published in 2012, received a considerable overhaul with the 2017 second edition. While some core ideas and chapters remained the same, the changes are extensive, with 10 of the 17 chapters being completely new for the second edition and the remaining chapters containing significant revisions. These revisions reflect not only new research but also the significant changes in YAL that occurred between the editions. The first edition of Teaching Young Adult Literature Today offered sound rationales for YAL's inclusion in the classroom, as well as overviews stabilizing different genres within adolescent literature, such as dystopian novels. Five years later, as YAL has continued to grow in popularity and has become somewhat more accepted in schools, the second edition takes a different approach by exploring the different ways the books can be utilized to teach different topics and reach adolescent readers inside and outside of the classroom.

The book consists of three main sections. The first, "Where Has YAL Been?," contains three chapters that provide useful background information on YAL, including its current state, the research that has been done on it, and the implications for classroom use. Section two, "Where is YAL Now?", unsurprisingly makes up the bulk of the text, with 11 chapters addressing topics ranging from how YAL can contribute to readers' understandings of poverty and impact anti-fat bias to how English language learners might benefit from reading adolescent literature. The book concludes with section three's "Where is YAL Going?", which explores the possibilities that integrating YAL with technology presents for readers and educators.

While numerous books address using YAL in the classroom, several aspects of Teaching Young Adult Literature Today make it a notable and worthwhile addition to educators' and scholars' libraries. Editors Hayn, Kaplan, and Karina R. Clemmons, who are YAL researchers and teacher educators with classroom experience, have assembled a thoughtful collection of chapters that speak to the needs of classroom teachers and academics alike. Many of the chapters in "Where is YAL Now?" offer specific, convincing rationales and strategies for integrating YA texts into the middle and high school classroom, with book recommendations, reading guides, and questions for teachers to use or adapt as needed. Additionally, these ideas for using YAL go beyond the obvious suggestions, as the proposed themes and perspectives are relevant to adolescent readers and the secondary curriculum while also being inventive. For instance, "Music and the Young Adult Novel: Assessing How Adolescents 'Read' the Music of Their Lives" by Steven T. Bickmore and Issac Bickmore recommends harnessing teenagers' knowledge of and interest in music through YAL books such as Eleanor and Park and This Song Will Save Your Life. Using these texts, students combine skills such as close reading and literary analysis with their cultural knowledge to create authentic products for assessment. Other chapters, including "Young Adult Literature as the Sustaining Force: An Interdisciplinary Approach to Teaching Environmentalism" by Kelly Byrne Bull and Juliann Dupuis, "Is Poverty the Result of Poor Decisions? What Young Adult Literature Contributes to the Conversation" by Crag Hill and Janine Darragh, and "Civil Rights and Social Justice: Then and Now - How Much Progress Have We Made?" by Barbara A. Ward, Deanna Day-

Study and Scrutiny: Research in Young Adult Literature 
Wiff, and Terrell A. Young, offer cross-curricular possibilities, allowing educators to expand their views of YAL's uses. Teaching Young Adult Literature Today also features chapters on updating YAL reading lists and utilizing YAL with English language learners, topics that remain relevant for classroom teachers.

For academics, including YAL scholars and teacher educators, this text also contains valuable insight and resources. For a college-level class on teaching YAL, the chapters noted above could provide strong background information by illuminating some of adolescent literature's pedagogical possibilities while exposing students to a wealth of notable titles. Additionally, the two sections that bookend the text, "Where Has YAL Been?" and "Where is YAL Going?" offer a plethora of vital information for those wanting to know about the past and future of YAL. "Where Has YAL Been?" examines recent YAL trends and research as well as the role the books have in teacher education. The topics in "Where is YAL Going?" invites readers to contemplate what is on the horizon for YAL, as the chapters consider how technology can enhance reading and teaching the books. The robust use of research throughout the chapters provides additional credibility to the ideas and gives scholars references to explore further.

\section{Young Adult Nonfiction: Gateway to the Common Core and Young Adult literature: Integrating, IMPLEMENTING AND RE-IMAgINING THE COMMON CORE}

Following the publication of the initial edition of Teaching Young Adult Literature Today, Hayn and Kaplan, along with Amanda L. Nolen and Heather Al. Olvey, edited Young Adult Nonfiction: Gateway to the Common Core, published in 2015, and Teaching Young Adult Literature: Integrating, Implementing, and Re-Imagining the Common Core, published in 2016. As the titles indicate, both books address YAL's potential in meeting the demands of the Common Core State Standards (CCSS). The conversation regarding the CCSS has become more muted since their unveiling in 2010; nevertheless, the Common Core is still very much a presence in schools, with 41 states having adopted the standards as of December 2018. Given their publication dates, Young Adult Nonfiction and Young Adult Literature are not as up-to-date as the most recent edition of Teaching Young Adult Literature Today. However, even as the commotion over the CCSS has died down and teachers have become more acclimated to the standards, these two texts still present a wealth of noteworthy ideas and resources.

Both books have the same general configuration, opening with a chapter that lays out the landscape of the CCSS and proposes sound justifications for how YAL can meet the standards' requirements and closing with a chapter on annotated resources. The other chapters address specific ways to employ YAL's potential in relation to the CCSS. As with Teaching Young Adult Literature Today, both books include recommended books and strategies for use as well as research that supports these ideas, which makes them beneficial for academics and future teachers. However, what makes these books distinct from Hayn and Kaplan's other text, and from each other, is their areas of concentration. Although the books might initially appear to cover similar ground, closer inspection shows that they discuss different facets of the same topic. Teaching Young Adult Literature gives a thoughtful and spirited argument 
for how YAL can meet the demands of the CCSS in general, while Young Adult Nonfiction's focus remains squarely on how teachers, especially those in disciplines besides English language arts (ELA), might use YA nonfiction.

For ELA teachers searching for ways to use YAL in the classroom or need support in justifying YAL to Common Core-focused colleagues, administrators, and parents, Teaching Young Adult Literature serves as an invaluable resource. Each chapter makes explicit references to the CCSS and YAL's potential applications in relation to the standards. Linda T. Parsons and Patricia E. Bandre examine the quantitative and qualitative measures of complexity of Maggot Moon and Code Name Verity in "Knowing Readers and Knowing Books: Using Text Complexity Measures to Select Texts and Motivate Adolescent Readers." While the contributors elect to assess two specific books, teachers can use their methods, which consider textual elements such as narration and language, to determine the complexity of other works. Besides helping teachers explain and use the different measures that must be considered when determining text complexity, this chapter also has great potential for use in teacher education courses to help challenge and expand future teachers' understanding of the issue. Other chapters in Teaching Young Adult Literature present ideas such as employing YAL to teach argumentative writing and utilizing adolescent literature in book clubs to meet a variety of Common Core reading standards.

Teaching Young Adult Literature's general approach might puzzle readers hoping for explanations of how YAL might be used to meet the CCSS's literacy requirements across the disciplines. Indeed, only one chapter (Crag Hill and Karina R. Clemmons's "Stimulating Health Dialogue and Evaluation: Implementations of Young Adult Literature to Address Common Core Standards in Health Classes") looks at interdisciplinary possibilities. Young Adult Nonfiction fills that gap. Written, in part, as a response to "the Common Core's push to include literacy across content areas" (Hayn, Kaplan, Nolen, \& Olvey, 2015, p.xi), the chapters include ways that various subject areas might utilize YA nonfiction to meet the CCSS's mandates for reading while also taking advantage of the rich educational opportunities YA books afford. As the introductory chapter notes, unlike textbooks, "trade books allow students to hone in on a particular event rather than a series of things that happened" (p.5). Using the CCSS as a foundation, the rest of the chapters involve specific ways that YA nonfiction books might be used to integrate science and English, enhance knowledge of STEM, and examine history from a different lens. Additionally, Young Adult Nonfiction also includes insight on how fictional young adult books can help students enter and better understand informational texts often featured in social studies classes. The attention to employing YA books across disciplines make Young Adult Nonfiction well-suited not just for ELA teachers' professional development and reference but also for educators in all areas who are searching for meaningful ways to meet the Common Core's reading standards.

Whether you are a classroom teacher looking for new ways to use YA texts in the classroom, a teacher candidate new to YAL, or a scholar who teaches about and studies adolescent literature, the triumvirate of Teaching Young Adult Literature Today, Young Adult Nonfiction, and Teaching Young Adult Literature is an indispensable resource. The books' integration of practical pedagogy with research allows them to meet the needs of a range of education stakeholders and makes them beneficial and high-quality additions to any professional library. 